\title{
Evaluating a sensitive issue: reliability of a clinical evaluation for allodynia severity
}

\author{
Tara L. Packham ${ }^{\mathrm{a}, \mathrm{b}}$ (D), Claude J. Spicher ${ }^{\mathrm{c}}$, Joy C. MacDermid ${ }^{\mathrm{a}, \mathrm{d}}$ (D), Isabelle Quintal ${ }^{\mathrm{e}}$ (D) and Norman Buckley \\ ${ }^{a}$ School of Rehabilitation Sciences, Institute of Applied Health Sciences, McMaster University, Hamilton, ON, Canada; ${ }^{\mathrm{b}}$ Regional \\ Rehabilitation Program, Hamilton Health Sciences, Hamilton, ON, Canada; ${ }^{C}$ Translational Neurosciences Institute, Department of \\ Neurosciences and Movement Sciences, Faculty of Sciences \& Medicine, University of Fribourg, Fribourg, Switzerland; ${ }^{\mathrm{d} M i c h a e l}$ G. DeGroote \\ Institute for Pain Research and Care, McMaster University, Hamilton, ON, Canada; ${ }^{\mathrm{O} S c h o o l}$ of Rehabilitation, University of Montreal, \\ Montreal, QC, Canada
}

\begin{abstract}
Purpose/Aim: Allodynia is a common feature of neuropathic pain with few validated clinical evaluation options. We identified a need to estimate the measurement properties of the standardised evaluation procedure for static mechanical allodynia severity popularised by the somatosensory rehabilitation of pain method, known as the rainbow pain scale. This study (www.clinicaltrials.gov. NCT02070367) undertook preliminary investigation of the inter-rater and test-retest reliability of the rainbow pain scale.

Methods: Persons with pain in one upper extremity after Complex Regional Pain Syndrome, a peripheral nerve injury or a recent hand fracture were recruited for assessment of static mechanical allodynia threshold using calibrated monofilaments by two raters at baseline, and repeated assessment one week later.

Results: Single measures estimates suggested inter-rater reliability was substantial for the rainbow pain scale [intra-class correlation coefficient $=0.78(n=31), p<0.001]$. Test-retest reliability was also excellent at with an intraclass correlation coefficient of 0.87 [ $n=28, p<0.001]$. However, confidence intervals suggest the true values could be more moderate, with lower bounds of the $95 \%$ confidence interval at 0.60 and 0.74 , respectively.

Conclusions: This pilot study has generated preliminary support for the inter-rater and test-retest reliability of the rainbow pain scale. Future studies should seek to increase confidence in estimates of reliability, and estimate validity and responsiveness to change in persons with somatosensory disorders.
\end{abstract}

Abbreviations: CRPS: complex regional pain syndrome; ICC: intraclass correlation coefficient; MPQ: McGill Pain Questionnaire; PNI: peripheral nerve injury; SMA: static mechanical allodynia; SRM: somatosensory rehabilitation method; VAS: visual analog scale

\section{KEYWORDS}

Neuropathic pain; allodynia; reliability; somatosensory rehabilitation; Rainbow Pain Scale

\section{Introduction}

Mechanical allodynia is a painful response to a non-nociceptive tactile stimulus (International Association for the Study of Pain n.d.), described as static or dynamic according to the delivery method of the stimulus. It may be associated with a specific nerve lesion in neuropathic pain, or suggest central sensitisation features in pain conditions such as complex regional pain syndrome (CRPS) or migraine (Woolf and Mannion 1999; Baron et al. 2012). Dynamic mechanical allodynia is typically measured by stroking the potentially painful skin with a brush. However, both the tools (type of brush) and technique (e.g., how long of a stroke is applied) are highly variable in the clinical setting, and it is often reported dichotomously as present or absent in the stated test location (Samuelsson et al. 2005). Consequently, it cannot be considered a threshold measurement. Brush allodynia testing is generally used for screening and diagnostic purposes and the responsiveness to change remains to be established (van Eijs et al. 2010). A need exists for clinically useful but accurate evaluations for the identification and quantification of allodynia, and monitoring of changing allodynia over time. Conversely, in the study of allodynia using animal models, the use of calibrated von Frey filaments to measure the threshold of static mechanical allodynia is common in laboratory practice (Koplovitch et al. 2012; Sorge et al. 2015).

Somatosensation has been defined as the '... detection, discrimination, and recognition of body sensations' (Dunn et al. 2013, p. S41): it encompasses touch, vibration, pressure, temperature, and pain sensations (Dunn et al. 2013). 'Somatosensory rehabilitation of pain' is the chosen terminology for a formal method developed by a Swiss certified hand therapist (CS) for the identification and treatment of neuropathic pain and reduced somatosensation following nerve lesion (Spicher et al. 2015). It is paradoxical that an area of numbness or decreased sensation - underlying hypoesthesia - is overlaid

CONTACT Tara L. Packham packhamt@mcmaster.ca E School of Rehabilitation Sciences, Institute for Applied Health Sciences, Room 403, McMaster University, Hamilton, ON, Canada 
with a hypersensitive area - allodynia (Spicher et al. 2008). The somatosensory rehabilitation method (SRM) is based on contemporary understandings of the function and dysfunction of the somatosensory nervous system (Spicher et al. 2015). In reference to allodynia, the clinical examination includes:

a. the need to precisely define the topographical territory demonstrating static mechanical allodynia (SMA) using a standardised application of a calibrated monofilament, known as allodynography (Spicher 2009; Spicher et al. 2008; Packham et al. 2019);

b. strategically considering the peripheral nerve branches residing in the painful territory to form a plausible neuroanatomic hypothesis (Finnerup et al. 2016; de Andrade Melo Knaut et al. 2017; Spicher et al. 2017) and

c. categorisation of the severity of the SMA with a series of calibrated monofilaments, known as the rainbow pain scale (Spicher et al. 2008; 2015; Nedelec et al. 2016).

Somatosensory rehabilitation for allodynia incorporates these three unique assessment components, and combines them with a self-reported evaluation of pain qualities to complete the clinical examination of neuropathic pain. The assessment results inform the application of the treatment modalities: a) the comfortable tactile or vibratory 'counter-stimulation' to a distant proximal zone of a neuroanatomically related cutaneous nerve branch, and b) strategic minimisation of evocative touch or activity (Spicher 2009).

However, there is a need to develop evidence systematically exploring the clinical measurement properties of reliability, validity and responsiveness to change for these assessment tools as an important prerequisite for building evidence for the effectiveness of the associated treatment methods. Further, a simple, standardised 'bedside' evaluation tool to screen for and quantify the severity of allodynia has potential benefits for both research and clinical practice.

\section{Purpose of the study}

The purpose of this study was to evaluate allodynia in persons with CRPS or peripheral nerve injury (PNI), and to estimate the measurement properties of the rainbow pain scale. Specifically, we wanted to address: Is the rainbow pain scale a reliable assessment tool that can be used during the clinical examination to document signs of sensory disturbance and categorise the severity of static mechanical allodynia?

\section{Materials and methods}

\section{Subjects and setting}

This prospective study took place in a hand therapy outpatient clinic at a regional trauma centre in Hamilton, Ontario as part of a larger pilot study (www.clinicaltrials.gov. NCT02070367) of somatosensory rehabilitation from September 2014 to January 2017. Inclusion criteria (confirmed by medical record) were 1) a diagnosis of CRPS meeting the Budapest research criteria (Harden et al. 2010) in a single upper limb OR 2) a unilateral
$\mathrm{PNI}$ in the upper limb verified intra-operatively, OR 3) a recent hand fracture (clinically stable but still requiring rehabilitation). The screening process for allodynia is described below. Target sample size for the explorations of reliability was set at $n=35$ using Donner's estimates to achieve substantial reliability at 80\% power over 2 test occasions (Donner and Eliasziw 1987). Baseline evaluations were conducted by a certified somatosensory therapist for pain (CSTP ${ }^{\circledR}$ ) (TP) and an independent evaluator (one of two experienced hand therapists, based on availability). The independent evaluators were provided with $6 \mathrm{~h}$ of training in the somatosensory evaluation methods. All participants gave written informed consent, and the study was approved by the local ethics committee (Hamilton Integrated Research Ethics Board).

\section{Evaluations}

Screening for SMA was conducted using a standardised set of questions. Participants were first asked to point (but not touch) to indicate the area of skin that was most painful to touch. They were asked to rate if the pain became worse with movement or touch, and/or if it occurred spontaneously (using the descriptors always, often, sometimes or never). This area was tested by the application of a single $2 \mathrm{~s}$ stimulus with a $15 \mathrm{~g}$ monofilament (after demonstration on their nonpainful limb): participants were asked if the stimulus produced pain of at least 3/10 (yes or no) on a Visual Analogue Scale (VAS). If yes, then the examiner proceeded with allodynography (this procedure and results are described in Packham et al. 2019) and the rainbow pain scale.

\section{Rainbow pain scale}

The rainbow pain scale uses seven different monofilaments, commonly known as von Frey filaments, to rate the severity of SMA within the allodynic territory identified by allodynography. With vision occluded, the centre of the previously mapped painful area is tested by applying a single touch stimulus with the smallest of the seven monofilaments $(0.04 \mathrm{~g} \# 2.44)$ for $2 \mathrm{~s}$. This process is repeated precisely on the same area of skin with progressively thicker filaments producing stronger stimuli (Figure 1) with an 8-second interval between applications, until the subject indicates the stimulus has become painful. As in allodynography, the standardised definition of pain is $30 \mathrm{~mm}$ on a $100 \mathrm{~mm}$ VAS, or pain at rest $+10 \mathrm{~mm}$ on a $100 \mathrm{~mm}$ VAS if pain at rest is more than $30 \mathrm{~mm}$. Testing is stopped as soon as a stimulus is perceived as painful: and the rainbow pain scale category is recorded (on the allodynography map) as the first size of filament to produce pain. Contrary to the clinical practice recommendations of the test developer (Spicher et al. 2008; 2015), it is noteworthy this was completed on the same occasion as the allodynography for pragmatic administration of the study protocol. It is also important to note if the initial screening for allodynia using the $15 \mathrm{~g}$ monofilament (\#5.18) was negative, this was recorded as a score of zero on the rainbow scale; the remaining monofilaments were coded from 1 (15 g \#5.18) to 7 ( $0.04 \mathrm{~g} \# 2.44$ ). 


\begin{tabular}{|c|c|c|c|c|c|c|c|}
\hline $\begin{array}{c}\text { Rainbow pain } \\
\text { scale rating }\end{array}$ & Purple & Indigo & Blue & Green & Yellow & Orange & Red \\
\hline $\begin{array}{c}\text { Monofilament } \\
\text { log [\#] }\end{array}$ & 5.18 & 4.93 & 4.56 & 4.17 & 3.84 & 3.22 & 2.44 \\
\hline Force & $15 \mathrm{~g}$ & $8.0 \mathrm{~g}$ & $4.0 \mathrm{~g}$ & $1.6 \mathrm{~g}$ & $0.8 \mathrm{~g}$ & $0.16 \mathrm{~g}$ & $0.04 \mathrm{~g}$ \\
\hline $\begin{array}{c}\text { Clinical } \\
\text { Interpretation }\end{array}$ & \multicolumn{2}{|c|}{ Discrete } & \multicolumn{2}{|c|}{ Significant } & \multicolumn{4}{|c|}{ Serious } \\
\hline
\end{tabular}

Figure 1. The rainbow pain scale. The rainbow pain scale is a categorical measurement of the intensity of allodynia: it is premised on the smaller a filament (lesser pressure) needed to produce a pain sensation, the greater the intensity of the allodynia. For testing an area of identified allodynia (e.g., post allodynography), the procedure starts with the 'red' filament (\#2.44), and then filaments of increasing pressure are applied with vision occluded until the person identifies the first size of filament that produces pain equivalent or greater to $3 / 10$ on a numeric rating scale. However, the person may perceive the application of smaller filaments sooner, but the test is continued until pain is elicited.

\section{Evaluation of pain qualities}

The McGill Pain Questionnaire (MPQ) is used in conjunction with the clinical examination signs of allodynography and the rainbow pain scale for outcome measurement within the somatosensory rehabilitation method (Melzack 2005) although most of the studies published to date use the French language version (Nedelec et al. 2016; Packham et al. 2018). While our goal for this investigation was not to measure outcomes, we thought it important to include a familiar measure of pain qualities to describe the population. We elected to use the original English version of the MPQ with its 78 pain descriptors divided into sensory and affective subscales (Boureau et al. 1992). The total number of words initially chosen as describing current pain is summed. These words are then rated using the descriptive scale [0 absent, 1 mild, 2 discomforting, 3 distressing, 4 horrible, 5 excruciating] to indicate the intensity of the most representative descriptor from each cluster. Following SRM recommendations (Spicher 2009), ratings were summed and converted to percentage score for ease of interpretation, for a total score tMPQ/100.

Assessments were completed by a trained independent evaluator at baseline, and the rainbow pain scale was repeated one week later to evaluate test-retest reliability. The allodynia screening procedure was repeated by the certified somatosensory therapist, followed by allodynography and the rainbow pain scale if allodynia was identified, thus testing inter-rater reliability. The evaluator was blinded to the location used by the other rater on the same occasion, and/or the location used for previous evaluation by the same rater a week earlier. Each evaluator used the same exact instruments (same monofilament kit). No additional treatments were initiated between the two assessments.

\section{Statistical analysis}

After data screening, demographics and clinical variables were described with means \pm standard deviations (SD) for continuous variables, and frequencies and percentages for categorical variables. To calculate test-retest and inter-rater reliability for the rainbow pain scale, intra-class correlation coefficients (ICCS) for individual measures were used. We also tested agreement between raters at baseline using
Spearman's rho because the rainbow scale could be considered categorical values, therefore requiring non-parametric approaches. Strength of correlations was quantified using Landis and Koch's (1977) recommendations, where $r=0-0.20$ is considered slight, $r=0.21-0.40$ is fair, $r=0.41-0.60$ is moderate, $r=0.61-0.80$ is substantial, and $r>0.80$ is considered excellent. All analyses were performed with STATA 13 (StataCorp LLC, College Station, Texas, USA), with statistical significance set at $p=0.05$ unless otherwise noted.

\section{Results}

Thirty-eight persons participated in this study: however, not everyone consented to complete all aspects of the evaluations; samples sizes are thus reported per analysis. Participants' demographic and clinical characteristics are summarised in Table $1 ; 12$ persons were identified to have SMA. Table 2 documents the frequency of static mechanical allodynia identified in each diagnostic group: there were significant differences between groups (Fisher's exact test $=0.045$ ); this has been reported previously (Packham et al. 2019).

Calculating the inter-rater reliability of the rainbow scale, we had 31 cases with complete data: 7 participants either declined to be tested a second time during the baseline visit or declined monofilament testing altogether because of pain or fear of pain. This yielded an ICC for single measures of $0.78[95 \% \mathrm{Cl} 0.60-0.89]$, and for average measures $=0.88$ [95\% Cl 0.75-0.94], $p<0.001$ for both. These could be interpreted as substantial for single measures, and excellent for average measures. Agreement between the two raters on the same occasion using Spearman's rho for the rainbow pain scale ratings was $r=0.87$. Test-retest reliability ( 1 week later, with no additional treatment in this interval) was completed with $n=28$ participants, yielding an excellent $\mathrm{ICC}_{2,1}=0.87[95 \% \mathrm{Cl}=0.74-0.94]$ for single measures and $\mathrm{ICC}_{2,1}=0.93 \quad[95 \% \mathrm{Cl}=0.85-0.97]$ for average measures, $p<0.001$ for both.

\section{Discussion}

This measurement study has produced preliminary estimates supporting the reliability of the rainbow pain scale for the categorisation of allodynia severity. Single measures 
Table 1. Participant demographics and baseline characteristics $(N=38)$.

\begin{tabular}{|c|c|c|c|}
\hline Characteristics & Mean & SD & Range \\
\hline Age & 45.9 & 14.4 & $15-76$ \\
\hline Duration of injury or pain (in months) & 17.9 & 38.5 & $1-168$ \\
\hline Grip strength (in kg) & $R=24.4$ & 19.2 & $0-63.3$ \\
\hline & $\mathrm{L}=26.6$ & 16.6 & $0-54.7$ \\
\hline$\%$ of normal grip in affected hand & $39.1 \%$ & 29.7 & $0-90.1 \%$ \\
\hline Total number of words from MPQ & 24.7 & 16.3 & $0-64$ \\
\hline Total MPQ score (tMPQ/100) & 38.3 & 26.4 & 0-93 \\
\hline Characteristics & Frequency & \multicolumn{2}{|c|}{ Percentage } \\
\hline Gender & $\begin{array}{l}M=19 \\
F=19\end{array}$ & \multicolumn{2}{|c|}{$\begin{array}{l}M=50 \% \\
F=50 \%\end{array}$} \\
\hline Diagnosis & $\begin{array}{l}\text { CRPS }=20 \\
\text { PNI }=10 \\
\text { Fracture }=8\end{array}$ & $\begin{array}{l}52.6 \% \\
26.3 \% \\
21.1 \%\end{array}$ & \\
\hline Dominance & $\begin{array}{l}R=32 \\
L=6\end{array}$ & \multicolumn{2}{|c|}{$\begin{array}{l}R=84 \% \\
L=15.8 \%\end{array}$} \\
\hline Side of injury & $\begin{array}{l}R=24 \\
L=14\end{array}$ & \multicolumn{2}{|c|}{$\mathrm{R}=63.2 \%$} \\
\hline $\begin{array}{l}\text { Patient-reported pain with } \\
\text { movement or touch }(n=35)\end{array}$ & $\begin{array}{l}\text { None }=4 \\
\text { Sometimes }=7 \\
\text { Often }=7 \\
\text { Always }=17\end{array}$ & $\begin{array}{l}\text { None } \\
\text { Somet } \\
\text { Often } \\
\text { Alway }\end{array}$ & $\begin{array}{l}.4 \% \\
=20 \% \\
48.6 \%\end{array}$ \\
\hline $\begin{array}{l}\text { Patient-reported spontaneous } \\
\text { pain }(n=35)\end{array}$ & $\begin{array}{l}\text { None }=7 \\
\text { Sometimes }=10 \\
\text { Often }=9 \\
\text { Always }=8\end{array}$ & $\begin{array}{l}\text { None } \\
\text { Somet } \\
\text { Often } \\
\text { Alway }\end{array}$ & $\begin{array}{l}\% \\
=28.6 \% \\
.7 \% \\
22.9 \%\end{array}$ \\
\hline $\begin{array}{l}\text { Allodynia present (reports pain with } \\
15 \mathrm{~g} \text { filament applied) }\end{array}$ & $\begin{array}{l}\text { Yes }=17 \\
\text { No }=18 \\
\text { Declined }=3\end{array}$ & $\begin{array}{l}\text { Yes }= \\
\text { No = } \\
\text { Declin }\end{array}$ & $\begin{array}{l}\% \\
\% \\
\% 7.9 \%\end{array}$ \\
\hline
\end{tabular}

Key: tMPQ: McGill Pain Questionnaire total score; CRPS: complex regional pain syndrome; PNI: peripheral nerve injury.

Table 2. Frequency of positive screening for static mechanical allodynia by diagnostic group $(n=35)$.

\begin{tabular}{lccr}
\hline Diagnostic group & No allodynia & Allodynia & Total \\
\hline CRPS & 6 & 12 & 18 \\
PNI & 5 & 4 & 9 \\
Fracture & 7 & 1 & 8 \\
Totals & 18 & 17 & 35 \\
\hline
\end{tabular}

Fisher's exact $=0.045$.

CRPS: complex regional pain syndrome; PNI: peripheral nerve injury.

estimates suggested the inter-rater reliability was substantial at ICC $=0.78$ to excellent at $r=0.87$. Donner and Eliasziw's (1987) estimates for the minimum number of subjects required to achieve 0.80 power for inter-rater reliability based on single ratings by 2 raters suggests 31 subjects would support fair reliability. Despite the potential underpowering of our estimates, illustrated in the resultant width of the confidence interval, all were statistically significant.

The test-retest reliability single measures estimate for the rainbow pain scale $(I C C=0.87)$ was better than that seen for inter-rater reliability $(I C C=0.78)$. This may suggest the greater volume of testing completed at baseline resulted in temporal and spatial summation (Woolf 2012) which would by definition increase the variability of pain perceptions (Backonja et al. 2013). Static mechanical allodynia was identified in both persons with CRPS and those with nerve injuries, but in different proportions (Fisher's exact test $=0.045$ ).

The series of calibrated monofilaments employed by the rainbow pain scale to categorically label the pain threshold for light touch can be used to add new detail to the mapping provided by allodynography (Packham et al. 2019). Both standardised clinical evaluations address unique aspects of the positive sensory phenomenon of static mechanical allodynia not quantified by standard electrophysiological testing (Yarnitsky and Pud 2004; Backonja et al. 2013). They make use of sensory evaluation equipment, and support the standardised evaluation of persistent and/or neuropathic pain (Walk et al. 2009; Haanpää et al. 2011; Uddin and MacDermid 2016) and can inform the planning of sensory reeducation treatments such as somatosensory rehabilitation (Packham et al. 2018). One final point should be made on the novelty of the rainbow pain scale as a clinical examination sign: it can only be considered relatively novel in humans. In literature describing testing of allodynia in rodent models (Gabriel et al. 2010; Koplovitch, Minert, and Devor 2012; Mogil 2012; Sorge et al. 2015) use of graduated von Frey filaments are standard practice. However, the target response in rodents is behavioural (paw withdrawal) (Koplovitch et al. 2012; Sorge et al. 2015) rather than a scalar expression of pain perception.

Protocols for using monofilaments to determine light touch sensation thresholds or sensory loss (including those advocated by the SRM) (Spicher et al. 2015) typically employ repeated application of each stimulus (Haanpää et al. 2011; Berquin et al. 2010). However, the rainbow pain scale is intended to determine the threshold for a painful perception associated with sensory gain. Accordingly, it relies on a standardised procedure of a single application of the stimulus for $2 \mathrm{~s}$ with vision occluded, followed by an inter-stimulus interval of at least $8 \mathrm{~s}$ to minimise the impact of delayed perception, after-sensations, and possible 'wind-up,' before applying the next (larger) stimulus. The reliability demonstrated in this study supports the adequacy of this approach. In clinical practice, the site is selected as the central point in the territory delineated by allodynography or as the worst pain point mentioned by the patient and is recorded on this map for reproducibility. However, for the purposes of our study, the evaluator was blinded to the location used by the other rater on the same occasion, and/or the location used for previous evaluation by the same rater a week earlier.

This protocol is in contrast to the repeated stimuli applied using the method of limits by Keizer et al. (2007) who used von Frey monofilaments to establish a minimum threshold of allodynia in persons with allodynia in a single limb. They asked the subjects to indicate the most painful area of the skin, and this was compared bilaterally by testing with progressively larger monofilaments. Once the person perceived 2 of 3 stimuli to be painful (most commonly at \#4.56 pressure), they were also asked to rate the intensity of the pain evoked: reporting a mean evoked pain of $6.8 / 10$ on a numeric rating scale (range 4-9). However, they reported none of their subjects found any size of monofilament to be painful on the non-affected limb, including an additional five healthy volunteers tested (Keizer et al. 2007). This is concordant with our findings of only 12 persons of the 38 tested meeting our criterion for allodynia (that is, perceiving pressure from a \#5.18 monofilament as evoking pain of at least 3/10 on a VAS). LaMotte et al. (1991) also described a variation of punctate pain testing using different sizes of nylon monofilaments to determine pain threshold in seven persons with experimental pain from capsaicin injection but 
concluded it was less useful than an alternate method involving repeated stimuli. However, formal estimates of reliability were not conducted.

Differences between the current study and previous descriptions of the SRM are also worthy of attention. The proposed target population for SRM, and the retrospective cohorts previously reported in the peer reviewed literature are more heterogenous in both the forms of neuropathic pain (Spicher et al. 2008) and/or in the anatomical locations of the pain (Spicher et al. 2008; Nedelec et al. 2016). While we also evaluated persons with peripheral nerve injuries or recent upper limb fractures, the primary focus was on complex regional pain syndrome of the upper limb. This is evident in the sample demographics, where $50 \%$ of the sample met the Budapest research criteria for CRPS, and may reflect both a selection and severity bias in our sampling. Accordingly, the measurement properties reported here may not generalise to more heterogenous samples.

\section{Limitations and recommendations for future research}

While Spicher et al. (2015) advocate completing the rainbow pain scale evaluation on a separate visit from the allodynography to avoid the effects of summation (Woolf 2012), this was not feasible given the additional inter-rater reliability demands of the study. Despite this, the inter-rater reliability estimates for the rainbow pain scale reflect substantial correlation (Landis and Koch 1977). It is also important to note that some participants declined repeated testing, or evaluation with monofilaments altogether. We cannot know if this group would represent important data that would influence the values and relationships reported here, although our general observation is this may reflect persons with chronic symptoms and negative pain beliefs. All of our participants had a history of upper limb injury, and the measurement estimates were on the basis of evaluations of the hand and upper limb. More research on the measurement properties of these evaluations should be conducted in larger samples including other cutaneous areas in the body, and other forms of neuropathic pain. Also, it was hypothesised in this study that mechanical allodynia represents neuropathic pain and peripheral nerve lesion. Future studies should include validated screening tools for neuropathic pain (Haanpää et al. 2011; Cappelleri et al. 2014) to confirm or challenge this supposition. We did not compare our findings to other well validated psychophysical tools for the evaluation of allodynia: we would encourage other researchers to pursue this form of criterion validation against other evaluation methods. Further, we did not report responsiveness as the small sample size represented by our pilot study of SRM treatment would not support meaningful estimates. Thus we advocate this work should be repeated in larger samples to add confidence for those already using these evaluation tools, and to support wider implementation of these tools for testing clinical examination signs.

\section{Conclusion}

This study reports initial investigation of the measurement properties of the rainbow pain scale, a standardised evaluation method for categorical measurement of the severity of static mechanical allodynia. Substantial to excellent interrater and test-retest reliability of the method is supported in persons with CRPS, peripheral nerve injuries, or pain after hand fracture when conducted by trained therapists. More study in larger and diverse samples, including estimates of criterion validity and responsiveness to change, will support continued use in research and clinical practice. The results presented here can inform the rigour and scope of those investigations.

\section{Acknowledgements}

The authors thank the staff and clients of the Hand Therapy Programme at Hamilton Health Sciences for their support in this endeavour. The authors thank Vicki Fraser, PT; Lisa Galant, OTReg(Ont); and Laura McMicking for their contributions to data collection and management.

\section{Disclosure statement}

Claude Spicher serves as the chief executive officer of the Somatosensory Rehabilitation Network. The other authors report no conflict of interest.

\section{Funding}

This work was supported by the New Investigators Fund [NIF\# 13344] at Hamilton Health Sciences. Tara Packham was also supported by a doctoral scholarship from the Canadian Institute of Health Research. Joy MacDermid is supported by a Canadian Institutes of Health Research Chair in Gender, Work, and Health and by the James Roth Chair in Musculoskeletal Measurement and Knowledge Translation. The monofilaments utilised in this study were generously donated by DanMic Global.

\section{ORCID}

Tara L. Packham iD http://orcid.org/0000-0002-5593-1975 Joy C. MacDermid (iD http://orcid.org/0000-0001-9311-7379 Isabelle Quintal (iD http://orcid.org/0000-0001-9466-2707

\section{References}

Backonja MM, Attal N, Baron R, Bouhassira D, Drangholt M, Dyck PJ, Edwards RR, Freeman R, Gracely R, Haanpaa MH, et al. 2013. Value of quantitative sensory testing in neurological and pain disorders: NeuPSIG consensus. Pain. 154:1807-1819.

Baron R, Förster M, Binder A. 2012. Subgrouping of patients with neuropathic pain according to pain-related sensory abnormalities: a first step to a stratified treatment approach. Lancet Neurol. 11:999-1005.

Berquin AD, Lijesevic V, Blond S, Plaghki L. 2010. An adaptive procedure for routine measurement of light-touch sensitivity threshold. Muscle Nerve. 42:328-338.

Boureau F, Luu M, Doubrère JF. 1992. Comparative study of the validity of four French McGill Pain Questionnaire (MPQ) versions. Pain. 50: 59-65.

Cappelleri JC, Bienen EJ, Koduru V, Sadosky A. 2014. Measurement properties of painDETECT by average pain severity. Clinicoecon Outcomes Res. 6:497-504. 
de Andrade Melo Knaut S, Packham TL, Spicher CJ, Buchet N, Quintal I, Sprumont P. 2017. Atlas of cutaneous branch territories: introduction, 2519 patients \& methods. E-News for Somatosensory Rehabilitation. 15:95-102

Donner A, Eliasziw M. 1987. Sample size requirements for reliability. Stat Med. 6:441-448.

Dunn W, Griffith JW, Morrison MT, Tanquary J, Sabata D, Victorson DE, Carey LM, Gershon RC. 2013. Somatosensation assessment using the NIH Toolbox. Neurology. 80:S41-S4.

Eijs F, Smits H, Geurts JW, Kessels AGH, Kemler MA, Kleef M, Joosten EAJ, Faber CG. 2010. Brush-evoked allodynia predicts outcome of spinal cord stimulation in complex regional pain syndrome type 1. Eur J Pain. 14:164-169.

Finnerup NB, Haroutounian S, Kamerman P, Baron R, Bennett DLH, Bouhassira D, Cruccu G, Freeman R, Hansson P, Nurmikko T, et al. 2016. Neuropathic pain: an updated grading system for research and clinical practice. Pain. 157:1599-1606.

Gabriel AF, Paoletti G, Della Seta G, Panelli R, Marcus MAE, Farabollini F, Carli G, Joosten E. 2010. Enriched environment and the recovery from inflammatory pain: social versus physical aspects and their interaction. Beh Brain Res. 208:90-95.

Haanpää M, Attal N, Backonja M, Baron R, Bennett $M$, Bouhassira $D$, Cruccu G, Hansson P, Haythornthwaite JA, lannetti GD, et al. 2011. NeuPSIG guidelines on neuropathic pain assessment. Pain. 152:14-27.

Harden RN, Bruehl S, Perez R, Birklein F, Marinus J, Maihofner C, Lubenow T, Buvanendran A, Mackey S, Graciosa J, et al. 2010 Validation of proposed diagnostic criteria (the 'Budapest Criteria') for complex regional pain syndrome. Pain. 150:268-274.

International Association for the Study of Pain. (n.d.). Taxonomy. [accessed 2017 Nov 18]. www.iasp-pain.org/Taxonomy.

Keizer D, van Wijhe M, Post WJ, Wierda JMKH. 2007. Quantifying allodynia in patients suffering from unilateral neuropathic pain using von frey monofilaments. Clin J Pain. 23:85-90.

Koplovitch P, Minert A, Devor M. 2012. Spontaneous pain in partial nerve injury models of neuropathy and the role of nociceptive sensory cover. Exp Neurol. 236:103-111.

LaMotte RH, Shain CN, Simone DA, Tsai EF. 1991. Neurogenic hyperalgesia: psychophysical studies of underlying mechanisms. J Neurophysiol. 66:190-211.

Landis JR, Koch GG. 1977. The measurement of observer agreement for categorical data. Biometrics. 33:159-174.

Melzack R. 2005. The McGill Pain Questionnaire: from description to measurement. Anesthesiology. 103:199-202.

Mogil JS. 2012. Sex differences in pain and pain inhibition: multiple explanations of a controversial phenomenon. Nat Rev Neurosci. 13 859-866.
Nedelec B, Calva V, Chouinard A, Couture MA, Godbout E, de Oliveira A, LaSalle L. 2016. Somatosensory rehabilitation for neuropathic pain in burn survivors. J Burn Care Res. 37:e37-46.

Packham TL, Spicher CJ, MacDermid JC, Buckley DN. 2019. Allodynography: reliability of a new method for objective clinical examination of static mechanical allodynia. Pain Med.

Packham TL, Spicher CJ, MacDermid JC, Michlovitz S, Buckley DN. 2018. Somatosensory rehabilitation for allodynia in complex regional pain syndrome of the upper limb: a retrospective cohort study. J Hand Ther. 31:10-19.

Samuelsson M, Leffler AS, Hansson P. 2005. Dynamic mechanical allodynia: on the relationship between temporo-spatial stimulus parameters and evoked pain in patients with peripheral neuropathy. Pain. 115: 264-272.

Sorge RE, Mapplebeck JCS, Rosen S, Beggs S, Taves S, Alexander JK, Martin LJ, Austin J-S, Sotocinal SG, Chen D, et al. 2015. Different immunce cells mediate mechanical pain hypersensitivity in male and female mice. Nat Neurosci. 18:1081-1083.

Spicher CJ. 2009. Handbook for somatosensory rehabilitation. Montpellier (France): Sauramps Medical.

Spicher CJ, Buchet N, Quintal I, Sprumont P. 2017. Atlas des territoires cutanés pour le diagnostic des douleurs neuropathiques. 3rd ed. Montpellier (Paris): Sauramps Médical.

Spicher CJ, Mathis F, Degrange B, Freund P, Rouiller EM. 2008. Static mechanical allodynia (SMA) is a paradoxical painful hypo-aesthesia: observations derived from neuropathic pain patients treated with somatosensory rehabilitation. Somatosens Mot Res. 25:77-92.

Spicher C, Quintal I, Vittaz M. 2015. Reeducation sensitive des douleurs neuropathiques. 3rd ed. Montpellier (France): Sauramps Medical.

Uddin Z, MacDermid JC. 2016. Quantitative sensory testing in chronic musculoskeletal pain. Pain Med. 17:1694-1703.

Walk D, Sehgal N, Moeller-Bertram T, Edwards RR, Wasan A, Wallace M Irving G, Argoff C, Backonja MM. 2009. Quantitative sensory testing and mapping - a review of nonautomated quantitative methods for examination of the patient with neuropathic pain. Clin J Pain. 25: 632-640.

Woolf CJ. 2012. Central sensitization: implications for the diagnosis and treatment of pain. Pain. 152:1-31.

Woolf CJ, Mannion RJ. 1999. Neuropathic pain: aetiology, symptoms, mechanisms, and management. Lancet. 353:1959-1964.

Yarnitsky D, Pud D. 2004. Quantitative sensory testing. In: Binnie CD, Coope R, Mauguiere F, Osselton JW, Prior PF, Tedman BM, editors. Clinical neurophysiology. Vol. 1. Amsterdam: Elsevier B.V.; p. 305-332. 